\title{
$\bullet$ \\ Application of Biometric Recognition for Patient Management System
}

\section{IJCRR}

Section: Healthcare

Sci. Journal Impact

Factor: 6.1 (2018)

ICV: 90.90 (2018)

(c) (7) (3)

Copyright@IJCRR

\section{Normahanim Abu Hassan', Nik Sakinah Nik Ab Aziz' ${ }^{1}$, Tanveer Shaikh'}

'School of Computing \& Technology, Asia Pacific University of Technology \& lnnovation Technology Park Malaysia, 5700 o Bukit Jalil, Kuala Lumpur, Malaysia.

\section{ABSTRACT}

Background: Studies have been conducted on a way to solve the problem related to healthcare in Malaysia. The healthcare in Malaysia has a few problems that affect the patients' satisfaction such as patients cannot access their own medical records, long waiting times at the registration counter and time-consuming for an emergency rescue mission by the paramedics.

Purpose: This research is a patient management system which is called MedCo can solve this problem by enabling the patient's personal information and brief medical records are accessible to the patient, paramedic and all users who are using the system by scanning the patient's fingerprint.

Conclusion: This can be used for registration at the registration counter as well as it can save a lot of time. The staff can scan the patient's fingerprint to access the patient's personal information and send it to the queue system. This system can be developed by using Dart programming language through Flutter for cross-platform development. This system will be build using Visual Studio Code and it requires the use of local_auth libraries to code for biometric recognition. Firebase and Google chrome will be used in the development process. This system will be developed for the mobile user that can support Android and iOS while for the desktop user, web applications will be developed.

Key Words: Biometrics, Fingerprint recognition, Identity management systems, Public healthcare, Privacy, Security

\section{INTRODUCTION}

The used of biometric recognition technology has been increasing day by day in both Malaysia and outside of Malaysia. Since biometric recognition captures individual unique characteristics, it is one of the must-have-features in a system for its biometric authentication as a form of identification and access control. It also has been used in airports, businesses, unlocking smartphones and increasingly popular among other features. There is a statistic that proved this statement by saying that over $75 \%$ of consumers have used biometric recognition with different unique characteristics which are fingerprint scanning, facial recognition, iris recognition, palm-vein scanning, signature dynamics, and hand geometry. ${ }^{1}$ According to an analysis by Grand View Research, the used of biometric technology has become common in many industries like healthcare, travel, financial and so on. The biometric recognition can be used for patient registration and identification in the hospital or clinic to reduce the waiting time for a check-up or even during an emergency.
This proposed system enables the patients to register their information at the registration counter only by using their fingerprint and the patient's brief medical record is accessible to the users, doctors, nurses, and paramedics. The patients need to go to the government hospital to register their fingerprints for the first time using the web application. All the information will be saved in the centralized database including their full name, address, emergency contact, blood type, disease and so on. When an emergency happens, paramedic or any people who installed the MedCo mobile application can identify them by scanning their fingerprint. The process will be faster as there will be a pop-up for the recent disease recorded and in-alert. The doctors and nurses can enter the patients' medical information in the database. Whenever the patients go to any hospital or clinic, they no need to register at the counter, they just scan their fingerprint for their information.

This system aimed to enable the users to register at the counter by scanning their fingerprint. To enable the paramedics or

\section{Corresponding Author:}

Tanveer Shaikh, School of Computing \& Technology, Asia Pacific University of Technology \& Innovation Technology Park Malaysia, 57000 Bukit Jalil, Kuala Lumpur, Malaysia; Email: tanveer.ks@apu.edu.my

ISSN: 2231-2196 (Print)

Received: 20.08 .2020
ISSN: 0975-5241 (Online)

Revised: 25.09 .2020
Accepted: 22.10 .2020 
other people to check the user's information and in-alert recent disease in case of emergency. To enable the doctors and nurses to access the patient's personal information, medical record, and medicine prescription before giving a treatment. This system is a cross-platform system so it can be used for mobile users through Android and iOS and for desktop users through the web application. This system will be used by the patients, non-patients, doctors, nurses, and paramedics.

In the literature review, the researcher will provide the previous study by other researchers. In the materials and methods, the researcher will provide the details on how the data gathering and analysis help the researcher with the quality of the project deliverable. In the results and discussions, the researcher will provide an analysis of data collected through any data gathering method chosen and a summary of the analysis. In the conclusion, the researcher will conclude the conference paper and its outcome.

\section{LITERATURE REVIEW}

Malaysia's healthcare services have been gradually improved their service towards a better service. ${ }^{2}$ Sean Kelly which is a chief medical officer at Imprivata has stated that biometric technology has been used in the healthcare industry as it accurately identifies people, and it maintains secure access to protect health information. ${ }^{3}$ Imprivata has claimed that fingerprint biometric identification has a false match rate of less than one in $1,000^{3}$. The used of biometric in this industry has brought a lot of benefits to the industry which is it provides a faster retrieval of patient data, accurate and up-to-date information and high efficiency. ${ }^{4}$

Malaysia healthcare services are changing towards wellness service which is opposite to illness service due to the main provider of health services, the Malaysian Ministry of Health $(\mathrm{MOH})$ providing a better healthcare financing mechanisms and managing and mobilizing a better healthcare services. ${ }^{2}$ Malaysia provides a dual-tiered system of healthcare services which consists of a government-led and funded public sector and a private sector. There are congestion and overcrowding that occur at the metropolitan public hospitals because of the population competing for a limited number of personnel and advanced technologies in small district medical facilities. ${ }^{5}$ The competitive health-seeking behaviour leads to reduced consultation time, overcrowding, low levels of understanding of patient problems and high prescribing levels at public health facilities due to irrational use of healthcare by the providers and the patients 5 . This has resulted that almost all patients were being registered within 15 minutes and the average total waiting time from registration to getting called to meet the doctor was 41 minutes and $99 \%$ of patients waited not more than 30 minutes to get their medication and the average consultation time was 18.21 minutes. $^{6}$
It is also time-consuming for a healthcare provider to obtain the patient's medical record and record, dictate, transcribe and arrange the information before any treatment administered. ${ }^{7}$ The author also claimed that when there is a case where the patient needs to be referred to another healthcare provider, the entire process of collecting information may have to be repeated. The author explained that it is very important to have the patient's full medical record because the absence of such data may lead to inappropriate diagnosis and treatment or one that is contradict with the patient's physiological condition such as having allergies. According to the author, the percentage of physicians who have great difficulty in accessing the patient records at the right time is $30 \%$ and $70 \%$ of hospital records appear to be incomplete. The patients also have no access to their medical records. ${ }^{8}$ Some of the hospitals in Malaysia used the MYHIX system and this system provides no access for the patient to their medical records. ${ }^{8}$

Ambulance response time (ART) is also one of the important parts in the health services as it is a standard key performance indicator (KPI) in measuring the emergency medical services (EMS) delivery performances. ${ }^{9}$ The paramedic team needs to acknowledge the patient's condition and personal information first before the ambulance departs as they would respond faster if they knew it was a trauma case or when children are involved and other treatments will require a long waiting time to get the treatments. ${ }^{9}$ The author explained that age and treatment types are one of the important factors that can affect the ambulance response time. Based on the research conducted by the author that evaluates 967 ambulances' emergency medical services, the average ambulance response time is 16.42 minutes which fail to reach the international standard KPI which is 8 minutes. ${ }^{9}$

Consumer demands have been increased as they expect for high technology in the Malaysia healthcare system ${ }^{10}$. High technology that in demands and emerges globally nowadays is biometric recognition. According to Gornley ${ }^{11}$, nowadays, hospitals in advanced countries are using biometric recognition such as iris and palm-vein scanning to overcome patient identification problem that has been increasing day by day. The same author also stated that the Pew Charitable Trusts with research firm Gartner Inc. predicted that by the year $2022,40 \%$ of the healthcare providers will use biometric recognition for patient identification. The biometric recognition system is a pattern recognition system that function by getting biometric data from a person and extract the feature set from the biometric data it gets and compare with the template set in the database ${ }^{12}$. According to Mogli, the process of verification or identification by using biometric recognition is first, the individual must present his or her biometric information to the system. Next, the system will automatically create a template and then compare the template created to the biometric information stored in the system. ${ }^{13}$ Then, it will 
be a matching action when the presentation template is compared to the enrolment template and if it is matched with each other, a score is generated based on the degree of similarity between the templates. ${ }^{13}$ Figure 1 shows the biometric system in a simplified way:-

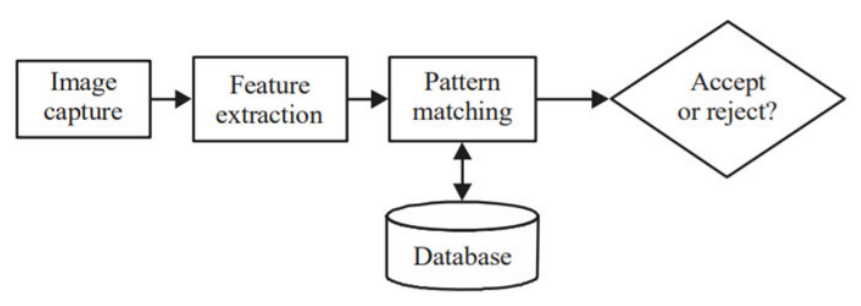

Figure 1: Biometric System14

Traditional methods of authentication which are by using passwords or PINs have been increasingly replaced by the used of biometric recognition technology, for example, biometric scanners on smartphones and other devices have to strengthen the security and ensure good customer experience. ${ }^{14}$ This is because the user of biometric technology can avoid to be forgotten, lost and forged like passwords and PINs. ${ }^{14}$ Biometric recognition has a lot of benefits to the patient management system which is one of the benefits is the hospital network can be biometrically protected from the hackers from getting the patients' information. ${ }^{13}$ The biometric technology also brings a benefit to the system as it is reliable as the person needs to be physically present to scan their fingerprint, iris, palm veins and so on to be authenticated. ${ }^{15}$ They also claimed that with the used of biometric recognition, the process will be fast, easy to use, less expensive authentication and accurate. Another author stated that it improves patient experience, protects data integrity, and saves money as there will be no duplicate record so the organization no need to waste their money to solve it. ${ }^{16}$

The fingerprint recognition system has been used widely globally, the most popular biometric system and actively researched among other biometric recognitions. ${ }^{17}$ This has been proved by statistic provided by Austin (2018), which concluded that $57 \%$ of organizations such as Apple, Lenovo and so on are using fingerprint scanning technology. In the third quarter of 2014, the smartphones' sales have increased by $20.3 \%$ and reach 301 million units. ${ }^{18}$ The authors also claimed that the sales have been increased because of the various mobile applications created and offered to the users in the App Store and Play Store. There are many platforms used for smartphones which are Android, Windows Phone, iOS, BlackBerry OS, Symbian, and others. Since the mobile application needs to be built faster and can be run on all platforms, a cross-platform mobile application is a solution $^{18}$. Cross-platform combines the pros of web application development and native application development then be- come a hybrid application development to enable multiplatform where the developers only need to code once to create the mobile application and make the deployment on different platforms. ${ }^{19}$

\section{MATERIALS AND METHODS}

The data gathering and analysishelped the researcher with the quality of the researcher's project deliverables. This is because the data gathered and analysed will let the researcher know about the demographic profile of participants such as the likelihood of the users or the percentage of the users who are prone to use this system once it is built. This data gathering and analysis helped the researcher to know about the feedbacks of the respondents on the current Patient Management System in Government Medical Facilities in Malaysia. This will let the researcher know whether the users are satisfied or not with the performance of the current system and if the percentage of the users are not satisfied with the services offered by the current system is higher than the one who satisfied, then the researcher can implement the solution to solve the problems in the system created. The data gathering and analysis help the researcher to know about the respondents' feedback on the technology such as mobile application, biometric recognition and so on. This is to make sure that the users are satisfied with the technology that will be used in the system. The researcher can know whether the features that the researcher offers in the system created is useful and important to the users or not. The data gathering and analysis help the researcher to know more about the current system that the health facilities used, the difficulties by using the current system and the expert's opinion on the system proposed by the researcher.

\section{Interview}

The researcher used this method by interviewing five interviewees which consist of two paramedics, two IT experts who work in the hospitals or clinics and one nurse. The researcher can conduct a Semi-structured interview. In this type of interview, the researcher will ask the prepared questions and expands to other questions. The researcher can ask the IT experts in the health facilities on what is the current system used in the hospital or clinic, then ask them the detailed of the systems.

\section{Questionnaire}

The researcher used this method by giving out an online questionnaire to the people. The online questionnaire is made by Google Forms. The questionnaire was given out to 51 respondents to answer. The participants are given a detailed explanation of the system and the consent form before answering the questions. 


\section{RESULTS AND DISCUSSION}

\section{Section A: Personal Medical Information}

\begin{tabular}{|c|}
\hline Question: \\
\hline $\begin{array}{l}\text { Do you need a guardian to look after you when you go out as a } \\
\text { precaution if the disease comes to attack? }\end{array}$ \\
\hline $\begin{array}{l}\text { Analysis: } \\
\text { Based on the finding, } 39.2 \% \text { of the respondents who have criti- } \\
\text { cal disease do not need a guardian while } 35.3 \% \text { of them need } \\
\text { a guardian. The number of respondents who have a critical } \\
\text { disease that needs a guardian is quite high with the difference } \\
\text { of only } 3.9 \% \text { with the majority. This indicates that the number } \\
\text { of patients who most need the in-alert disease feature is lower } \\
\text { than the one who least needs it. }\end{array}$ \\
\hline
\end{tabular}

\section{Section B: Respondent's Feedbacks on Patient Management System in Government Medical Facilities in Malaysia.}

\begin{tabular}{|l|}
\hline Question: \\
\hline I can easily access my disease history. \\
\hline Analysis: \\
Based on the finding, 43 out of 51 respondents disagree and \\
strongly disagree that they can easily access their medical \\
records. This indicates that the patients are restricted and have \\
no access to their medical record (8). \\
\hline
\end{tabular}

\section{Section C: Technology used by respondents}

\begin{tabular}{|l|}
\hline Question: \\
\hline $\begin{array}{l}\text { Have you ever used any mobile application related to medical } \\
\text { or health? }\end{array}$ \\
\hline $\begin{array}{l}\text { Analysis: } \\
\text { Based on the finding, } 64 \% \text { of the respondents have used any } \\
\text { mobile application related to medical or health while } 35 \cdot 3 \% \\
\text { have not used it. This indicates that the respondents find it } \\
\text { useful to have a mobile application which manages their medi- } \\
\text { cal record and monitor their health and so on. }\end{array}$ \\
\hline
\end{tabular}

\section{Analysis of data collected through Interview}

Analysis of data collected through interview with Paramedics.

\section{Question 1:}

What is the difficulties in handling patient in an emergency in terms of accessing the patient medical history or medicine prescription? Is there any alert from the patient's family that the patient have an in-alert disease?

\section{Analysis:}

The paramedic have difficulties in accessing the patient personal information. This is because they only can check the patient personal information through their Identity Card. If the Identity Card is cannot be found, the patient is remain unknown until its family come looking for them or until the patient become fully conscious. The paramedic cannot access the patient medical record. They can only ask the detailed of the patient including personal information and medical record through the caller. There is a difficulty in giving the first aid treatment as they do not know what is the disease history of the patient, thus they only can give a general first aid treatment such as injection to stabilize the patient and so on.
The liquid injected (normal saline) used is suitable for all human with or without allergy. Thus, there are no chances of the patient that allergic to that liquid. Even if the patient is an allergy to any chemical substances, the paramedic will check it based on the allergy card that the patient has or they can ask it directly to the patient. This first aid treatment will be done based on the dispatcher who will guide the paramedic on what to do to the patient through the walkie talkie. The paramedic can only access to the patient medical record once they are arrived at the hospital and with permission of the doctor.

\section{Analysis of data collected through interview} with Nurse

\section{Question 2:}

What is the process during the registration at the registration counter?

\section{Analysis:}

In the past, the patient who is first come to the hospital will be registered by filling up the form then they will be given a registration number, but as the technology emerges, the user only needs to give their identity card, then the user will be given a registration number. That registration number is used to store the patient information including personal information and medical records. The next time the patient comes, the patient needs to give their Identity Card's number to the registration counter. The staff at the registration counter will search the Identity Card's number in the system and retrieve the patient information by using the registration number.

\section{Analysis of data collected through interview with IT experts.}

\begin{tabular}{|l|}
\hline Question 3: \\
\hline Can the patient easily access their medical history? \\
\hline Analysis: \\
The patient cannot access their medical history as patient \\
information is very private and confidential and if the patient \\
wants to see their medical records, they need to go to the \\
Jabatan Rekod Hospital (Medical Record Department). \\
\hline
\end{tabular}

\section{CONCLUSION}

This conference paper had cover 7 parts that discussed different areas related to the proposed project. At the end of the first leg of the project, the researcher achieved knowledge on how to build the system. This paper discussed how is the patient management system in Malaysia, what is biometric recognition and its user feedback, what is cross-platform and its advantages. The researcher achieved the knowledge and information that is needed for the development process by collecting through questionnaire and interview. The researcher also achieves the requirement and feedback from the people regarding the system proposed through questionnaire and interview. The data collected is analysed and useful to the project so that the researcher can make changes or retain the requirements. The researcher achieves a knowledge on how to manage time well and how to delegate and prioritize the 
tasks so that the project will be completed before the due date.

\section{REFERENCES}

1. Liu, Shanhong. Biometric technologies - Statistics \& Facts. [Online] 2019. https://www.statista.com/topics/4989/biometrictechnologies/.

2. Thomas S, Beh L, Nordin RB. Health care delivery in Malaysia: changes, challenges and champions. J Pub Health Afr 2011;2(2).

3. Donna M. Managed Healthcare Executive. 2019. Accessed August 2020. https://www.managedhealthcareexecutive.com/article/why-biometrics-are-future-patient-care.

4. Aware. Biometrics in healthcare: Improved safety and privacy for patients. 2019. Accessed August 20202. https://www.aware. com/biometrics-in-healthcare/.

5. Mohd-Tahir NA, Paraidathathu T, Li SC. Quality use of medicine in a developing economy: Measures to overcome challenges in the Malaysian healthcare system. SAGE open medicine. 2015;3:2050312115596864.

6. Thapa R, Saldanha S, Bucker N, Rishith P. An Assessment of Patient Waiting and Consultation Time in the Outpatient Department at a Selected Tertiary Care Teaching Hospital. J Evol Med Dent Sci 2018;7(8):984-989.

7. Jayabalan M, O'Daniel T. Access control and privilege management in electronic health record: a systematic literature review. J Med Syst 2016;40(12):261.

8. Ministry of Health Malaysia. Malaysia Health Information Exchange (MyHIX) Toolkit. s.1.: Ministry of Health Malaysia, 2014.

9. Chin SN, Cheah PK, Arifin MY, Wong BL, Omar Z, Yassin FM, Gabda D. Determinants of ambulance response time: A study in Sabah, Malaysia. InAIP Conference Proceedings 2017 Apr 27 (Vol. 1830, No. 1, p. 080003). AIP Publishing LLC.

10. Merican MI, Rohaizat Y, Haniza S. Developing the Malaysian health system to meet the challenges of the future. Med J Malaysia 2004;59(1):84.

11. Iquii. Biometric Recognition: definition, challenge and opportunities of biometric recognition systems. [Online] 2018. Accessed August 2020. https://medium.com/iquii/biometric-recognitiondefinition-challenge-and-opportunities-of-biometric-recognition-systems-d063c7b58209.

12. Dhir VI, Acet AS, Kumar R, Singh G. Biometric recognition: A modern era for security. Int J Eng Sci Technol 2010;2(8):33643380 .
13. Mogli G. Role of Biometrics in healthcare privacy and security management system. Sri Lanka J Bio-Medical Informatics 2012 Jun 7;2(4).

14. Yang W, Wang S, Hu J, Zheng G, Valli C. Security and accuracy of fingerprint-based biometrics: A review. Symmetry. 2019 Feb;11(2):141.

15. Kumar S, Walia E. Analysis of various biometric techniques. International Journal of Computer Science and Information Technologies. 2011;2(4):1595-1597.

16. Roth, Mandy. Health Leaders: Biometric technology for patient identity. [Online] 2018. [Cited: January 2, 2019.] https://www. healthleadersmedia.com/innovation/biometric-technology-patient-identity-4-things-know.

17. Thamizhvani TR, Chandrasekaran R, Dhivya AJ, Jain UR, Mukundhan D, Kumar HV. A review on biometric Technology in Healthcare. Ind J Pub Heal Res Dev 2019;10(5):800-804.

18. El-Kassas WS, Abdullah BA, Yousef AH, Wahba AM. Taxonomy of cross-platform mobile applications development approaches. Ain Shams Eng J 2017;8(2):163-190.

19. De Andrade PR, Albuquerque AB, Frota OF, Silveira RV, da Silva FA. Cross platform app: a comparative study. arXiv preprint arXiv:1503.03511. 2015 Mar 11.

20. Epilepsy Research UK. [Online] 2020. [Accessed August 2020.] https://www.epilepsyresearch.org.uk/poll-shows-that-almost50-of-people-forget-to-take-their-medication-at-least-once-amonth/.

21. Heath, Sara. Long Appointment Wait Time a Detriment to High Patient Satisfaction. [Online] 2018. [Cited: January 22, 2020.] https://patientengagementhit.com/news/long-appointment-waittime-a-detriment-to-high-patient-satisfaction.

22. Bachman, John W. The Problem with Patient Satisfaction Scores. [Online] 2016. [Accessed August 2020.] https://www. aafp.org/fpm/2016/0100/p23.html.

23. National Institutes of Health. One-Third of Adults with Diabetes Still Don't Know They Have It. [Online] 2006. [Accessed August 2020.] nih.gov/news-events/news-releases/one-thirdadults-diabetes-still-dont-know-they-have-it.

24. Healy, Melissa and McDaniels, Andrea K. About 15 percent of Americans with HIV don't know they're infected, CDC says. [Online] 2017. [Accessed August 2020.] https://www.baltimoresun.com/health/bs-hs-knowing-hiv-status-20171130-story. html.

25. Australia, University of Western. 50 percent of people do not know they have high blood pressure. [Online] 2019. [Accessed August 2020.] https://medicalxpress.com/news/2019-05-percent-people-high-blood-pressure.html. 